\title{
Conhecimento e Atitudes sobre Genética entre Médicos Residentes
}

\author{
Knowledge and Attitudes on Genetics Among \\ a Group of Medical Residents
}

\author{
Patrícia Santana Correia \\ Pedro Vitiello \\ Maria Helena Cabral de Almeida Cardoso ${ }^{I}$ \\ Dafne Dain Gandelman Horovitz
}

\section{PALAVRAS-CHAVE \\ - Genética \\ - Educação \\ - Grupos focais \\ - Opinião pública \\ - Médicos residentes}

\section{KEYWORDS}

- Genetics

- Education

- Focus groups

- Public opinion

- Medical residents

Recebido em: 29/04/2010

Reencaminhado em: $11 / 11 / 2010$

Aprovado em: 09/12/2010

REVISTA BRASILEIRA DE EDUCAÇÃO MÉDICA

\section{RESUMO}

O objetivo deste trabalho foi estudar o conhecimento, as crenças e opiniões sobre Genética em um grupo de médicos residentes. Foi utilizada a técnica de grupos focais com 12 residentes de Pediatria em seu primeiro mês de curso, divididos em quatro grupos. Para a análise do material, foi escolhida a técnica da leitura isotópica. Os participantes demonstraram pouco interesse pelo assunto, mas tinham um grau razoável de conhecimento. Este conhecimento, entretanto, era pouco vinculado à prática clínica, sugerindo a necessidade de reformulação da formação médica. Os grupos mostraram consciência da alta prevalência e da grande morbidade das doenças genéticas, sinalizando que a nova geração de médicos pode ser mais sensível à questão da inserção da Genética na saúde pública. O Brasil está passando por um momento de transição epidemiológica, com o aumento proporcional das doenças de etiologia genética como causas de morbi-mortalidade, tornando necessária a inclusão dessas condições no planejamento para a gestão da saúde pública.

\begin{abstract}
This article focuses on knowledge, beliefs, and opinions related to genetics among a group of medical residents. Twelve residents in pediatrics, divided into four focus groups, were interviewed during their first month of residency. The material was analyzed using the isotopic reading technique. Participants showed little interest in the topic, despite having a reasonably good level of knowledge, which bore little relationship to their clinical practice, suggesting the need to reformulate medical education. The groups were aware of the high prevalence and morbidity of genetic disorders, thus signaling that the new generation of physicians may be more sensitive to the need to include medical genetics in public health. Brazil is currently experiencing an epidemiological transition, with a proportional increase in genetic disorders as a cause of morbidity and mortality, thus requiring such inclusion in public health planning.
\end{abstract}




\section{INTRODUÇÃO}

Em países em desenvolvimento, como o Brasil, as doenças relacionadas à pobreza ainda são a principal causa de mortalidade infantil, mas esses países estão passando por uma transição epidemiológica, com um aumento relativo dos fatores genéticos como causa de doença e morte. No Brasil, os defeitos congênitos estavam em $5^{\circ}$ lugar como causa de mortalidade infantil em 1980 e passaram a ser a segunda causa em 2000. As doenças de etiologia genética estão relacionadas com internações prolongadas e onerosas e altas taxas de mortalidade hospitalar. Por serem doenças crônicas, há necessidade de tratamento contínuo e multiprofissional, envolvendo serviços médicos, de reabilitação e educação especial ou inclusiva ${ }^{1}$.

Apesar disso, a inserção das doenças genéticas e dos defeitos congênitos nos programas de saúde pública no Brasil vem ocorrendo de forma lenta. Em relação ao cuidado, existem os programas de tratamento da osteogênese imperfeita, iniciado em 2001, e da doença de Gaucher, em 1995. Para prevenção e monitorização de defeitos congênitos, há os programas de fortificação da farinha de trigo com ácido fólico (prevenção de defeitos de tubo neural), o Programa Nacional de Imunização (prevenção de rubéola congênita), o Programa Nacional de Triagem Neonatal (diagnóstico precoce de fenilcetonúria, hipotireoidismo congênito e, em alguns estados, hemoglobinopatias e fibrose cística), e a implantação do campo 34 da Declaração de Nascimento (registro de anomalias congênitas observadas ao nascimento) $)^{2,3}$.

Em números absolutos, a prevalência de doenças genéticas e malformações congênitas nos países em desenvolvimento é igual ou superior a dos países desenvolvidos. Essa alta prevalência, associada ao alto custo social e à possibilidade de prevenção dessas condições, em alguns casos, justifica o investimento na área da genética médica, mesmo em países com outros problemas de saúde pública ${ }^{4}$ Em 2003, a Organização Mundial de Saúde promoveu um encontro tratando de Genética Médica e Comunitária na América Latina, do qual saíram algumas recomendações. Dentre elas, destacaram-se a educação dos profissionais de saúde em Genética e dos geneticistas em saúde pública e a promoção de uma melhor interação entre os geneticistas clínicos, os profissionais de saúde pública, os profissionais de Atenção Primária à Saúde e as organizações comunitárias ${ }^{5}$.

Concomitantemente ao aumento proporcional do papel dos defeitos congênitos na morbi-mortalidade da população brasileira, muitos avanços relacionados ao diagnóstico, à prevenção e ao tratamento dessas condições vêm ocorrendo. Assim, um número cada vez maior de indivíduos são candidatos a usar as também crescentes novas tecnologias. Mas, no Brasil, a maioria dos pacientes e famílias acometidos por doenças pu- ramente genéticas, ou influenciadas pelos genes, desconhece amplamente a condição médica que possuem, não tendo sido investigados de maneira adequada para evidenciar os fatores genéticos envolvidos. O País se encontra, portanto, no passo inicial do atendimento em Genética Clínica, que é o de incrementar medidas que possibilitem um sistema de atendimento pelo qual a maioria da população tenha acesso a serviços e procedimentos que possam revelar a doença genética que possuem. A partir disso, poderão entender sua condição de saúde e as alternativas disponíveis para tratamento e prevenção ${ }^{6}$.

Em janeiro de 2009, foi instituída, por meio de Portaria do ministro da Saúde ${ }^{7}$ a Política Nacional de Atenção Integral em Genética Clínica, no âmbito do Sistema Único de Saúde (SUS), objetivando, entre outras coisas, o cuidado integral aos pacientes com condições genéticas, o incentivo à pesquisa e a educação continuada dos profissionais de saúde participantes da implantação dessa política. Um ano depois, muito pouco foi feito a respeito desses objetivos, e a Portaria que regulamentaria definitivamente a Genética Clínica no SUS sequer foi publicada8

Dados mundiais e nacionais sugerem que a maioria dos médicos não especialistas em Genética tem algum conhecimento básico da especialidade, porém é incapaz de fornecer informação e orientação adequadas sobre doenças dessa natureza e procedimentos relacionados. Como o primeiro contato dos pacientes com doença genética usualmente é com um médico generalista, com quem desenvolvem uma relação de confiança, estes têm um papel fundamental no encaminhamento e orientação dos pacientes. Em países onde não há serviços de Genética em número suficiente, o paciente pode ser acompanhado apenas pelo médico de Atenção Primária. Por esse motivo, esses médicos necessitariam receber uma formação bem melhor que a atual, para que o papel de orientador seja cumprido satisfatoriamente $\mathrm{e}^{9-12}$.

Segundo Rosa e Solomon ${ }^{13}$, apenas ensinar o que há de mais atual em Genética aos estudantes de Medicina não é suficiente para que eles apliquem seus conhecimentos de forma a beneficiar seus futuros pacientes. Também é necessário ensiná-los o valor do conhecimento da vida diária e de que forma se pode transitar entre este saber e o acadêmico, buscando contribuições de ambos. Dessa forma, durante as sessões de aconselhamento genético, as questões que afligem seus pacientes podem ser mais bem compreendidas pelo médico e respondidas de forma mais objetiva e clara, atendendo ao interesse daquela pessoa em particular.

Diante do exposto, há necessidade de se conhecer melhor a situação dos médicos brasileiros em relação à Genética. $\mathrm{O}$ objetivo deste trabalho é conhecer os conceitos e opiniões a respeito de temas de Genética em um grupo de médicos recém-formados, iniciando a residência em Pediatria. 
Foram escolhidos médicos recém-saídos da faculdade pelo interesse em obter a opinião de generalistas, ainda sem especialização, mas já em contato com pacientes, cuja formação, por ser recente, incluiu aspectos de Biologia Molecular. A opção por residentes de Pediatria se deu porque, dentre as especialidades médicas, a Pediatria é uma das que tem maior contato com pacientes com doenças genéticas/defeitos congênitos, tornando os pediatras os médicos não geneticistas com maior probabilidade de ter interesse e conhecimento na área. Além disso, os pediatras estão em posição privilegiada para funcionarem como conselheiros genéticos, por usualmente terem contato com as famílias dos seus pacientes. No entanto, um artigo de revisão de trabalhos publicados entre 1960 e 2005 mostrou que residentes de Pediatria têm um treinamento deficiente em Genética e dificuldade em transmitir informações e de fazer o aconselhamento genético de seus pacientes e respectivas famílias, sugerindo a necessidade de haver mudanças no currículo da residência em Pediatria ${ }^{11}$.

\section{METODOLOGIA}

Os 12 médicos que formavam a turma do $1^{\circ}$ ano de residência em Pediatria em um hospital geral federal foram reunidos em grupos focais para discussão durante seu primeiro mês de residência. Eram dois homens e dez mulheres, todos formados há menos de um ano, provenientes de quatro universidades públicas e quatro particulares. Cada participante recebeu um código alfanumérico, de M1 a M12, utilizado para identificá-lo nas citações de suas intervenções ao longo do texto.

Foi escolhida a metodologia de grupos focais, por ela permitir observar as atitudes, sentimentos, crenças, experiências e reações de um grupo de uma maneira que não seria possível se fossem utilizados outros métodos, como a simples observação ou entrevistas convencionais ${ }^{14-16}$. Os residentes foram divididos em quatro grupos de três participantes cada um, e cada grupo participou de uma única sessão, com duração de 60 a 90 minutos. Esses pequenos grupos de três participantes são chamados de tríades e têm algumas particularidades em relação aos grupos focais tradicionais, formados de seis a doze pessoas ${ }^{14,17}$. A principal vantagem é promover uma discussão mais aprofundada de cada tópico do assunto escolhido, geralmente em um tempo mais curto do que nos grupos de tamanho maior. Os grupos pequenos também permitem o surgimento de opiniões individuais no lugar de um "pensamento grupal" e podem ser realizados no próprio local de trabalho ou estudo dos participantes, não necessitando de instalações especiais. A principal desvantagem é a limitação na variedade de opiniões emitidas e na interação entre os participantes. Outra desvantagem é o maior desconforto para os participantes, que têm que emitir suas opiniões com mais frequência e mais intensamente do que quando existem mais pessoas participando da discussão ${ }^{17}$.

A pesquisa foi aprovada pelo Comitê de Ética em Pesquisa do Instituto Fernandes Figueira e um Termo de Consentimento Livre e Esclarecido foi lido e assinado por todos os participantes. O moderador dos grupos era um especialista em Genética Médica, que conduziu a discussão segundo roteiro preestabelecido. O roteiro teve o objetivo de garantir que todas as questões de interesse fossem discutidas, mas nem sempre foi seguido na ordem apresentada e nem todas as perguntas foram formuladas de maneira explícita - quando os assuntos surgiam espontaneamente, eram discutidos naquele momento. Um auxiliar acompanhou as sessões, controlando o tempo e anotando a discussão. As sessões tiveram a duração de cerca de uma hora, tendo sido gravadas e, após o término dos encontros, transcritas e analisadas.

Para a análise do material foi escolhida a técnica que Ciro Flamarion Cardoso, com base em Greimas, chama de leitura isotópica. Isotópicas são as categorias semânticas redundantes que tornam possível a leitura uniforme do texto. Com o apoio das categorias semânticas isotópicas, passamos da microssemântica - o significado isolado de cada frase ou enunciado à macrossemântica - a significação do discurso completo. Essa passagem é feita em três etapas: primeiro é feito o exame comparativo das partes que contém um texto, descobrindo suas categorias de significação subjacentes; em seguida, são isoladas as categorias que se repetem, que são as categorias isotópicas; finalmente, tais categorias são distribuídas pelos níveis semânticos do discurso: figurativo, temático e axiológico.

O nível figurativo é relacionado à percepção do mundo real, em geral aludindo a um dos cinco sentidos. O nível temático é aquele em que se agrupa os elementos figurativos em temas; e o nível axiológico é aquele em que se identifica as oposições, os juízos de valor que o texto possa manifestar ${ }^{19}$.

\section{RESULTADOS E DISCUSSÃO}

As categorias isotópicas presentes no que foi verbalizado pelos participantes dos grupos focais organizaram-se em quatro eixos temáticos: o primeiro referente aos conceitos básicos de Genética; o segundo, à Genética aplicada à Medicina; o terceiro relacionado aos testes diagnósticos e preditivos; e o quarto, à genômica e à manipulação genética.

Para analisar o que foi dito pelos médicos, ainda que recém-formados, foi considerado o modo de pensar médico. Esse modo de pensar é o que Ludwik Fleck ${ }^{20}$ chama de estilo de pensamento, que pode ser definido como "uma construção definida do pensamento que leva a uma forma particular de pensar, ver e agir em vez de qualquer outra" (p.64). O estilo de pensamento não é uma característica voluntária, mas uma imposição fei- 
ta pelo processo de socialização representado pela inclusão em um coletivo de pensamento, definido como "uma comunidade de pessoas mutuamente trocando ideias ou mantendo interação intelectual" (p.39). Um coletivo de pensamento consiste em um pequeno círculo de especialistas que efetivamente produzem conhecimento - o círculo esotérico, e outro maior - o círculo exotérico, constituído pelos "leigos educados".

O círculo esotérico pode ser subdividido em uma região mais interna de experts especializados e uma mais externa, de experts generalistas. Um coletivo de pensamento é formado por vários desses círculos em intersecção. Um indivíduo pode fazer parte de vários círculos exotéricos, mas de bem poucos ou mesmo de nenhum círculo esotérico. A comunicação entre os experts especializados é feita por meio dos periódicos técnicos/ científicos e dos livros de referência, já o círculo exotérico se informa a partir de periódicos de ciência popular ou de divulgação. Entre essas duas formas de comunicação há o manual básico, que funciona como uma introdução ao círculo esotérico.

$\mathrm{O}$ estilo de pensamento médico pode ser caracterizado como pragmático e direcionado à busca de informações relevantes à prática clínica, priorizando fontes academicamente confiáveis $^{21}$. Esse fato transpareceu na linguagem utilizada pelos participantes, demonstrando familiaridade com os termos técnicos nas referências constantes à prática médica e na preocupação em deixar clara a necessidade de obter informações de fontes consideradas confiáveis - livros e artigos científicos. Todos negaram ler sobre o assunto em jornais e revistas "leigos" ou ver programas de televisão, mesmo que como estímulo para buscar informações mais detalhadas em outros locais. É pouco provável que, em um mundo em que a Genética é popular tanto no noticiário quanto na ficção, os médicos deixem de entrar em contato com esse assunto no dia a dia. Logo, o desprezo por fontes de informação "não científicas" pode ocorrer porque eles, embora expostos, não as levem em consideração, ou porque se policiaram para não demonstrar interesse por elas durante as discussões.

Entretanto, em relação a áreas como Biologia Molecular e Genética, os médicos clínicos podem ser considerados como similares aos "leigos educados". Seu conhecimento vem, no máximo, dos manuais básicos, situando-os na fronteira entre os círculos esotérico e exotérico. Eles podem ter acesso aos periódicos científicos da área, mas dificilmente têm as ferramentas necessárias para os lerem criticamente ${ }^{21}$. Talvez por esse motivo, a maioria reconheceu ler pouco sobre Genética.

O uso da Internet foi pouco mencionado, e foi citada apenas a utilização de bancos de dados como o Medline, ou seja, fontes confiáveis. Isso se contrapõe ao artigo de Hughes et al. ${ }^{22}$ que mostrou que mais de $50 \%$ dos médicos jovens utilizam a
Internet, especialmente sites como Google e Wikipedia, para pesquisa e tomada de decisões clínicas.

Todos os grupos se mostraram pouco entusiasmados pelos temas propostos, tendo sido necessário formular quase todas as perguntas do roteiro para iniciar a discussão, pois os assuntos raramente surgiam de forma espontânea. Em alguns momentos, a sessão do grupo focal foi mais semelhante a uma entrevista em grupo, mas a interação entre os participantes e o surgimento de novos tópicos para discussão, não trazidos pelo moderador, característica dos grupos focais, ocorreram em todos, ainda que de forma reduzida. Como a participação foi mais ativa quando se falava de assuntos ligados à prática médica, com exemplos práticos relacionados a pacientes e doenças, a discussão ficou muito centrada nesse tema.

\section{OS QUATRO EIXOS TEMÁTICOS}

\section{A Genética Básica}

Quando solicitados a falar o que primeiro vinha à mente ao ouvirem a palavra genética, os grupos mencionaram cromossomos - XX e XY, DNA, seus componentes e expressões relacionadas, como dupla-hélice, além de lembrarem da Genética Clínica. Quando perguntados sobre conceitos básicos em Genética, todos os conheciam e eram capazes de usá-los de forma correta, ainda que superficial e simplificada. Os conceitos foram citados como quase autoexplicativos, e os participantes não foram capazes de aprofundá-los. Algumas vezes a explicação era feita com palavras informais, com familiaridade, como quando uma das participantes fala que um cromossomo:

$$
\text { "É o DNA todo enroladinho, uma minhoquinha" (M11). }
$$

Houve sempre referências à Genética como uma matéria da faculdade, algumas vezes considerada difícil ou tediosa. M5 justifica seus possíveis enganos nas respostas logo de início:

\footnotetext{
"Genética me lembra aquelas traduções, aquelas transcrições que caem na prova, horrorosas [...] Eu repeti Genética. Já falei que eu sou uma pessoa péssima para esta discussão".
}

A Genética Médica também foi lembrada na forma de comentários sobre pacientes e doenças de etiologia genética. Houve poucas referências à Genética fora do contexto acadêmico/hospitalar, apenas nas menções aos alimentos transgênicos e à clonagem ou em comentários jocosos, como na resposta à pergunta:

“O que é um mutante?" — "É uma novela da Record!" (M7).

Desde meados da década de 1990, o DNA e os genes fazem parte das conversas comuns, de propagandas e programas de ficção, e há um grande entusiasmo popular a respeito 
do assunto ${ }^{23,24}$. Mas para os participantes, os primeiros pensamentos sobre Genética se relacionam mais com suas vidas profissionais do que com o dia a dia, apesar das eventuais descrições coloquiais dos conceitos.

As metáforas para o DNA surgiram espontaneamente. A maioria considerou que impressão digital era uma boa maneira de pensar sobre o DNA, por traduzir exclusividade e individualidade. A metáfora do DNA como uma "receita de bolo" - lista de ingredientes e instruções a serem seguidas para construir um organismo - foi julgada como excessivamente simples, sem dar conta dos fatores ambientais que contribuem para o fenótipo. Alguns autores ${ }^{25,26}$ consideram a metáfora da receita adequada para explicar o funcionamento do DNA de forma não reducionista exatamente por ser simples e capaz de contemplar aspectos ambientais, mas apenas M10 acrescentou que o ambiente poderia ser representado pelo "forno". Entretanto, para explicar o que é DNA para um paciente, todos concordaram que a metáfora da receita seria a escolhida, devido à sua clareza.

A rejeição de uma metáfora considerada mais simples e clara, utilizável apenas para transmitir conhecimento a "leigos" também está de acordo com o estilo de pensamento médico. Segundo Fleck (1979) 20: "Qualquer comunicação e, de fato, toda a nomenclatura tende a fazer de qualquer item de conhecimento mais exotérico e popular [...]. Certeza, simplicidade e vivacidade se originam no conhecimento popular" (p.114).

\section{A Genética Médica}

Embora a maioria dos residentes participantes tenha tido pouco contato com a especialidade durante a faculdade, todos a conheciam e tinham noção da dinâmica de atendimento de um geneticista - consulta ambulatorial semelhante à de outras especialidades, mas mais demorada, com ênfase no diagnóstico clínico e alguns exames complementares específicos. Houve menção à pesquisa, porém com um peso menor em relação à clínica.

Quanto ao tipo de paciente atendido pelo geneticista, esse foi considerado complexo - razão pela qual precisaria de um especialista que pudesse dar conta dessa complexidade. Para alguns dos participantes, o geneticista seria um clínico especializado em pacientes com múltiplas comorbidades. Ao contrário, para outros, ele é um médico que faz apenas diagnóstico e não acompanha seus pacientes. Em comum há o pensamento de que o geneticista teria a solução dos problemas dos pacientes complicados, como dizem M7 e M8, respectivamente:

\footnotetext{
"Aquela criança em que alguma coisa não está batendo, que é estranha, é hora do parecer [do geneticista]"

"Com o geneticista teria um acompanhamento melhor".
}

Quando solicitados a descrever essas crianças, sempre surgiu a palavra sindrômica - frequentemente utilizada como sinônimo de dismórfica, embora a classificação em síndromes clínicas seja utilizada no raciocínio diagnóstico de todas as especialidades médicas, não só da Genética Clínica. Características dismórficas, como alterações em olhos e mãos e "orelhas baixas", também foram citadas. A importância dada pelos pediatras ao posicionamento das orelhas para a suspeição de síndromes genéticas foi comentada por Leite (2002), que também ressalta que esse sinal é bem pouco específico, tendo pouco valor diagnóstico ${ }^{27}$. A única condição genética familiar a todos os residentes foi a síndrome de Down. Outras condições foram mencionadas em relação a experiências isoladas com pacientes durante o internato, consideradas marcantes pela raridade ou complexidade do quadro clínico.

Houve preocupação em todos os grupos em enfatizar o não determinismo genético, como pode ser percebido em afirmações como:
"Meu DNA não sou eu" (M4)
"A Genética participa, tem um peso [na determinação do que uma pessoa é], mas não é exclusiva" (M10).

Ter um gene para alguma doença, como o câncer, foi interpretado como ter uma predisposição. A influência dos genes foi considerada bem mais decisiva nas características físicas, na fisiologia e nas doenças, com o ambiente tendo maior peso na personalidade. Os estudos com gêmeos - nos quais ambientes diferentes supostamente determinariam personalidades discordantes - foram citados como prova do peso do ambiente.

A incidência de más-formações congênitas foi um pouco superestimada pelos grupos, entre 5 e 10\% — segundo a organização March of Dimes, é em torno de $3 \%{ }^{28}$. As causas mais frequentemente citadas foram as ambientais - drogas, medicações, álcool, fumo e radiação. A relação entre misoprostol e síndrome de Moebius foi sempre mencionada. Dentre as causas genéticas, foram citadas a consanguinidade e a idade materna avançada como fatores de risco e apenas um grupo lembrou as doenças recessivas como causas de má-formação. Em nenhum grupo foi discutida a etiologia multifatorial - a mais frequente para malformações isoladas ${ }^{29}$. Quando perguntados sobre prevenção primária, as respostas foram imediatas, aparentemente decoradas - "Não fumar, não beber, não usar drogas...". A indicação do uso de ácido fólico periconcepcional para a prevenção de defeitos de tubo neural era conhecida por todos, mas só foi citada quando perguntados diretamente sobre medicações a serem utilizadas na prevenção de defeitos congênitos. 


\section{Os Testes Genéticos}

Há pouco conhecimento a respeito de testes genéticos, referidos apenas como "exames de DNA" ou pela função, como em:

"Quando a mãe tem dois filhos com o mesmo defeito, estuda para saber se veio do pai, se veio da mãe ou dos dois" (M6).

O único exame citado nominalmente por todos foi o cariótipo. Todos foram conservadores em relação à indicação desses testes, considerando, de um modo geral, que não deveriam ser feitos em pessoas saudáveis, mas apenas em casos em que haja histórico familiar ou após alguma coisa dar errado, como o nascimento de bebês com defeito congênito. Os testes foram considerados auxiliares, não substituindo medidas preventivas tradicionais, como a mamografia na prevenção do câncer de mama, por exemplo. Essa ideia vai ao encontro das recomendações atuais, já que de 80 a $85 \%$ dos cânceres de mama são esporádicos, surgindo em mulheres sem histórico familiar ou mutações constitucionais ligadas a um risco aumentado ${ }^{30}$. Foi enfatizada a necessidade de prevenção primária de doenças em qualquer pessoa, não apenas naquelas com risco genético aumentado.

A não compreensão dos resultados dos testes preditivos surgiu como uma preocupação, pois os leigos teriam dificuldade em compreender riscos. Mesmo para esses médicos essa dificuldade existe, principalmente se a doença a ser testada for grave, como disse M10:

"Eu vou confessar que se eu soubesse que tinha uma mutação para câncer de mama eu ia achar que ia ter a doença, eu tenho pavor".

$\mathrm{Na}$ vida "real", isto é, fora do ambiente do aconselhamento genético, as pessoas falam sobre suas características supostamente herdadas como fatos concretos, tornando o gene algo material, passível de "dar defeito". Não há espaço para incertezas e possibilidades, que são parte fundamental dos resultados probabilísticos dos testes genéticos. O conceito de risco, por ser abstrato, é de difícil compreensão, não auxiliando na tomada de decisões de médicos e pacientes ${ }^{24,31}$. Mesmo especialistas em aconselhamento genético têm dificuldades em lidar com probabilidades, o que os leva muitas vezes a preferir informar os riscos aos pacientes em palavras, como "alto" e “baixo” e não em números ${ }^{32}$.

Outro receio em relação aos testes foi o da interferência na vida das pessoas, como separação de casais ou preocupação com problemas a respeito dos quais "não há nada a fazer" seja porque não há tratamento para a condição testada ou para os exames pré-natais, seja porque o aborto é proibido no Bra- sil. A indicação dos testes foi caracterizada como uma função deles, médicos, o que fica claro nas declarações:

"Eu não gostaria que um paciente fizesse um exame de rastreio, eu preferia não saber" (M5)

"Para uma pessoa saudável, eu não faria" (M8).

Em nenhum momento foi mencionada a possibilidade do paciente querer ou não ser submetido a um determinado teste genético ou mesmo que eles, os pacientes, tomem a iniciativa de solicitar por si mesmos os exames. Entretanto, segundo Rose $^{31}$, para que as novas tecnologias genéticas, que permitem o estabelecimento de riscos e os diagnósticos pré-sintomáticos, sejam utilizadas adequadamente, deve haver uma modificação na relação entre os médicos e seus clientes. Essa relação não pode mais ser a tradicional, paternalista, na qual os médicos dão conselhos e ditam comportamentos. É necessário conhecer e aplicar os princípios do consentimento informado, da autonomia e do não direcionamento.

\section{Genômica e manipulação genética}

A evolução das técnicas de manipulação genética foi considerada como inevitável, permitindo que, em um futuro próximo, seja possível utilizá-las para modificação de características e tratamento de doenças, embora reconheçam que nem todas possam vir a ser tratadas dessa forma. Para alguns, isso já é possível em determinados casos, à semelhança dos alimentos geneticamente modificados, e o maior fator limitante são os impedimentos éticos. A possibilidade de manipulação de embriões foi vista como perigosa, sujeita a erros inesperados, abusos e graves consequências sociais e éticas. $\mathrm{O}$ temor da eugenia fica claro nas menções a "bebês perfeitos, louros de olhos azuis" e no repúdio à manipulação para modificar características fenotípicas não patológicas. Entretanto, a manipulação para tratar/curar doenças foi considerada algo positivo.

Para características como inteligência houve controvérsia, com alguns se mostrando favoráveis, principalmente se esse tipo de manipulação se tornasse comum e socialmente aceito. Nesse momento, a discussão ficou mais pessoal, com algumas referências ao que eles próprios fariam ou gostariam que fosse permitido, e não apenas a como agiriam em relação aos pacientes. Talvez por isso as fontes confiáveis tenham sido deixadas de lado e expressões como "chegou aos meus ouvidos", "acho que isto acontece" tenham surgido. Chamou a atenção o fato de que, embora todos tenham tido um discurso não reducionista quando falaram do papel do DNA nas características físicas e mentais, pouco se falou na possibilidade da manipulação genética não obter o efeito desejado devido a interações não esperadas com o meio. 
Em relação à clonagem, houve menção à ovelha Dolly e aos possíveis problemas e complicações causados pela técnica, como o envelhecimento precoce. A clonagem reprodutiva foi condenada, com argumentos principalmente religiosos, como os apresentados por dois participantes:

$$
\begin{aligned}
& \text { "Deus vai brigar com a gente" (M5) } \\
& \text { "Você clona o corpo e o resto [a alma]?" (M1). }
\end{aligned}
$$

A clonagem terapêutica, de órgãos, foi considerada aceitável. Em três dos quatro grupos havia participantes que acreditavam ser possível que um clone humano já tenha sido feito.

\section{CONSIDERAÇÕES FINAIS}

Esta foi uma pesquisa qualitativa, com a intenção de levantar algumas questões em um grupo de jovens médicos provenientes de várias universidades no início de sua formação como especialistas.

Chamou a atenção o pouco interesse pela Genética demonstrado pelos jovens médicos, mesmo neste grupo de futuros pediatras, cujo contato com pacientes com doenças genéticas é mais frequente, comparado com outros especialistas. $\mathrm{O}$ desinteresse se refletiu em certa apatia durante as sessões, mas o tamanho reduzido dos grupos pode também ter contribuído nesse ponto, pois não houve discussões que estimulassem a participação de todos.

Por um lado, devido à sua formação, os médicos consideram os meios de divulgação científica para leigos, que tratam do tema de forma atraente, como inadequados e não merecedores de atenção, embora alguns mitos, como a clonagem humana, tenham surgido nas discussões. Por outro, o ensino da Genética durante a faculdade a torna desinteressante, sendo mais uma matéria a ser decorada, sem relação com a prática médica. As novas tecnologias em Genética vêm evoluindo rapidamente, trazendo modificações no perfil dos usuários e nas relações entre médicos e pacientes, e a formação médica precisa se modificar para acompanhar essas mudanças.

Os participantes demonstraram um razoável conhecimento dos conceitos básicos de Genética, embora carecessem de experiência prática no assunto. Essa inexperiência pode em parte ser explicada por serem recém-formados. Outro motivo é o fato dos currículos das faculdades de Medicina não aproximarem de forma adequada o conhecimento básico, como a Biologia Molecular, por exemplo, da prática clínica. Por essa razão, esses residentes eram capazes de "recitar" termos técnicos, mas não de nomear testes genéticos comuns e suas indicações. Uma reformulação no currículo, com ênfase na aplicabilidade clínica do conhecimento básico, é necessária, inclusive, para torná-lo mais atraente aos estudantes. Além disso, poderiam ser fornecidas orientações sobre como utilizar o conheci- mento do cotidiano "não médico" para enriquecer sua própria formação e sua relação com os pacientes, não só em Genética, mas em todas as áreas da Medicina.

Também foi percebida pouca familiaridade com a Genética Clínica como especialidade, seja pela falta de um especialista no hospital onde receberam treinamento ao longo do internato médico, seja pelo pouco contato deste com as demais especialidades. O geneticista foi visto como alguém sobrecarregado, que atende pacientes complicados, a quem se recorre quando "não se sabe mais o que fazer". Entretanto, todos reconheceram que os geneticistas são clínicos que valorizam a semiologia médica e não necessariamente utilizam tecnologias dispendiosas e de alta complexidade, aproximando o seu trabalho do cotidiano médico.

A relação médico-paciente ainda foi vista pelo grupo de maneira tradicional, desconsiderando a possibilidade de que os pacientes ou suas famílias possam ter um papel mais ativo nas escolhas relacionadas à sua saúde, sugerindo que esse tema também deve ser revisto durante a formação médica.

O reconhecimento pelos participantes da alta prevalência e da grande morbidade das doenças genéticas, associado à visão da Genética como especialidade clínica, podem sinalizar que a nova geração de médicos seja mais sensível à questão da inserção da Genética na saúde pública. É importante a consciência de que, embora o Brasil ainda sofra com males típicos do subdesenvolvimento, o momento é de transição epidemiológica, com o aumento proporcional dos defeitos congênitos e das doenças de etiologia genética como causas de morbi-mortalidade. São condições frequentemente graves e incapacitantes, porém passíveis de serem diagnosticadas, tratadas e eventualmente prevenidas, muitas vezes com uma simples consulta médica. Por esse motivo, o diagnóstico e o tratamento das malformações congênitas/doenças genéticas, assim como o aconselhamento genético das famílias afetadas, deveriam ser incluídos no planejamento para a gestão da saúde pública no País.

O conhecimento das concepções sobre Genética entre os médicos é necessário para que as políticas públicas de saúde a respeito do tema sejam planejadas, considerando quem vai aplicá-las na prática diária, e também para que modificações no currículo das escolas médicas possam ser feitas de forma adequada.

\section{REFERÊNCIA}

1. Horovitz DDG, Llerena Júnior JC, Mattos RA. Atenção aos defeitos congênitos no Brasil: panorama atual. Cad Saúde Pública.2005;21(4):1055-64.

2. Horovitz DDG, Mattos RA, Llerena Júnior JC. Medical genetic services in the state of Rio de Janeiro, Brazil. Community Genet. 2004;7:111-7.

3. Castilla EE, Luquetti DV. Brazil: Public Health Genomics. Public Health Genomics 2009;12:53-8. 
4. Penchaszadeh V, Christianson A, Giugliani R, Boulyjenkov V, Katz M. Services for the prevention and management of genetic disorders and birth defects in developing countries. Community Genet. 1999;2:196-201.

5. Kofman-Alfaro S, Penchaszadeh VB. Community Genetic Services in Latin America and Regional Network of Medical Genetics. Community Genet. 2004;7:157-9.

6. Brunoni D. Aconselhamento genético. Ciênc Saúde Colet. 2002;17(1).

7. Brasil. Ministério da Saúde. Portaria no. 81, de 20 de janeiro de 2009. Institui, no âmbito do Sistema Único de Saúde (SUS), a Política Nacional de Atenção Integral em Genética Clínica. Diário Oficial da União 2009; 21 jan.

8. Sociedade Brasileira de Genética Médica [homepage]. Genética no SUS. Disponível em www.sbgm.org.br/noticias_ genetica_sus.asp

9. Asai A, Ohnishi M, Nishigaki E, Sekimoto M, Fukuhara S, Fukui T. Focus group interviews examining attitudes toward medical research among the Japanese: a qualitative study. Bioethics. 2004;18(5):448-70.

10. Howlett NJ, Avard D, Knoppers BM. Physicians and genetic malpractice. Med Law. 2002; 21(4):661-80.

11. Rosas-Blum E, Shirsat $P$, Leiner M. Communicating genetic information: a difficult challenge for future pediatricians. BMC Med Educ. 2007;18(7):17.

12. Rim PHH, Magna LA, Ramalho AS. Genetics and prevention of blindness. Arq Bras Oftalmol. 2006;69(4):481-5.

13. Rosa VL, Solomon J. When science and the public meet: training for genetic counseling. Public Understand. Sci. 1998;7:271-84.

14. Krueger R. Focus Groups: A Practical Guide for Applied Research. Thousand Oaks: Sage Publications; 2004

15. Gibbs A. Focus Groups. Social research update; 1997.19.

16. Bates B. Public culture and public understanding of genetics: a focus group study. Public Understand Sci. 2005;14:47-65.

17. Edmunds H. The focus group research handbook. Chicago: NTC business books; 1999.

18. Kerr A, Cunninghan-Burley S, Amos A. Drawing the line: an analysis of lay people's discussions about the new genetics. Public Understand Sci. 1998;7:113-33.

19. Cardoso C. Narrativa, Sentido, História. Campinas: Papirus; 1997.

20. Fleck L. Genesis and Development of a Scientific Fact. Chicago: University of Chicago Press; 1979.

21. Camargo Júnior KR. Sobre palheiros, agulhas, doutores e o conhecimento médico: o estilo de pensamento dos clínicos. Cad Saúde Pública. 2003;19(4):1163-74.
22. Hughes B, Joshi I, Lemonde $H$, Wareham Junior J. physician's use of Web 2.0 for information seeking and medical education: a qualitative study. Int J Med Inform. 2009; 78(10):645-55.

23. Nelkin D, Lindee S. The DNA Mystique: The Gene As a Cultural Icon. New York: W.H. Freeman Press; 1995.

24. Duden B, Samerski S. Pop genes: an investigation of the gene in popular parlance. In: Burri R e Dumit J. Biomedicine as Culture. Instrumental Prectices, Tecnoscientific Knowledge, and New Modes of Life. New York-London: Routledge; 2007. p.167-89.

25. Condit C, Condit D. Blueprints and Recipes: Gendered Metaphors for Genetic Medicine. J Med Humanit. 2001;22(1):29-39.

26. Lippa R. Gender, nature, and nurture. Mawah: Lawrence Erlbaum Associates, Inc.; 2002.

27. Leite JCL. Orelhas: a importância de seu posicionamento no diagnóstico de uma criança de aspecto sindrômico. J Pediatr. 2002;78(6):533-4.

28. March of Dimes. [homepage]. Disponível em http:// www.marchofdimes.com/

29. Nussbaum RL, McInnes RR, Huntington FW, Thompson MW. Thompson \& Thompson Genetics in Medicine. Philadelphia: Elsevier; 2004.

30. Godinho ER, Koch, HA. Rastreamento do câncer de mama: aspectos relacionados ao médico. Radiol Bras. 2004;37(2):91-9.

31. Rose N. The Politics of Life Itself: Biomedicine, Power, and Subjectivity in the Twenty-First Century. Princeton Univ Press; 2006.

32. Michie S, Lester K, Pinto J, Marteau T. Communicating Risk Information in Genetic Counseling: An Observational Study. Health Educ Behav. 2005;32(5):589-98.

\section{CONTRIBUIÇÃO DOS AUTORES}

Todos os autores participaram da concepção do artigo. Patrícia S. Correia, Dafne D. G. Horovitz e Maria Helena C. A Cardoso participaram da redação e revisão do artigo. Patrícia S. Correia e Pedro Vitiello participaram das sessões dos grupos como moderadora e auxiliar, respectivamente.

\section{CONFLITO DE INTERESSES}

Declarou não haver.

\section{ENDEREÇO PARA CORRESPONDÊNCIA}

Patrícia Santana Correia

Instituto Fernandes Figueira — Fiocruz

Av. Rui Barbosa, 716

Flamengo - Rio de Janeiro

CEP. 22250-020

E-mail: correia.pat@gmail.com 